\title{
A CRIANÇA CONTEMPORÂNEA E A NOÇÃO DE CUIDADO: UMA REFLEXÃO A PARTIR DA FENOMENOLOGIA HERMENÊUTICA
}

\author{
The Contemporary Child and the Notion of Care: A Reflection from the Hermeneutic \\ Phenomenology
}

\section{El Niño Contemporáneo y la Noción de Cuidado: Una Reflexión a partir de la Fenomenología Hermenéutica}

\section{L'Enfant Contemporain et la Notion de Soins : Une Réflexion Basée sur la Phénoménologie Herméneutique}

10.5020/23590777.rs.v21iEsp1.e9492

\author{
Maira Prieto Bento Dourado iD 9 \\ Doutoranda e Mestra em Estado e Sociedade, UFSB; Especialista em Psicologia Clínica Fenomenológico-Existencial, IFEN; Psicóloga, UERJ.
}

\section{Resumo}

Partindo da perspectiva heideggeriana sobre o ser-aí, apresento uma compreensão da criança na contemporaneidade tendo como fio condutor a noção de cuidado para compreender os modos de ser do homem no ciclo inicial da vida. Utilizei a fenomenologia como metodologia qualitativa, articulando a teoria à prática clínica da autora em psicoterapia infantil. Primeiramente, apresento uma discussão teórica sobre cuidado embasada na filosofia de Heidegger, dialogando com autores afins. Posteriormente, um aprofundamento bibliográfico sobre o percurso histórico das formas de se relacionar com a criança e como acumulam novos conceitos e padrões. Por fim, apresento uma perspectiva heideggeriana do ser-aí da criança. A condução da criança ao psicoterapeuta envolve dificuldades denominadas cientificamente de "distúrbios", que se referem ao não ajustamento a modelos normativos constituídos na sociedade e na cultura. São determinações históricas acerca do sentido da experiência infantil e constituem o espaço em que o ser do homem se constitui, mas é preciso pensar de que modo esse homem está em jogo em sua constituição. Em Heidegger, o cuidado se encontra na ontologia dos fenômenos e precede qualquer "atitude" ou "situação" vivida, é estar em jogo na sua existência. O filósofo defende que a criança pertence a uma fase cronológica do ser-aí, não há diferenciação entre ser-aí criança ou ser-aí adulto, e aponta a inclinação atual por diagnósticos, que fecham o homem como substância que possa ser examinada, medida e tratada como objeto. "Verdade", "diagnóstico" e "cura" são palavras que se encaixam no pensamento calculante da ciência moderna, da técnica, e se revelam no discurso dos pais. O espaço terapêutico de cuidado permite a compreensão da criança não a partir de determinações a priori, mas sim naquilo que aparece: a criança será, então, compreendida a partir das suas próprias significações.

Palavras-chave: criança; psicoterapia; cuidado; Heidegger.

\section{Abstract}

Starting from the Heideggerian perspective on the being-there, I present an understanding of the child in contemporaneity, having as a guiding thread the notion of care to understand the ways of being of man in the initial cycle of life. I used phenomenology as a qualitative methodology, linking theory to the author's clinical practice in child psychotherapy. First, I present a theoretical discussion on care based on Heidegger's philosophy, dialoguing with like-minded authors. Subsequently, a bibliographical analysis on the historical path of the ways of relating to the child and how they accumulate new concepts and patterns. Finally, I present a Heideggerian perspective of the child's being there. The conduct of the child to the psychotherapist involves difficulties scientifically called "disorders", which refer to the non-adjustment to normative models constituted in society and culture. These are historical determinations about the meaning of childhood experience and comprise the space in which man's being is set up, but it is necessary to think about how this man is at game in his constitution. In Heidegger, care is found in the ontology of phenomena and precedes any "attitude" or "situation" experienced, which means to be at stake in their 
existence. The philosopher argues that the child belongs to a chronological phase of being-there, there is no differentiation between beingthere as a child or being-there as an adult and points out the current inclination towards diagnoses, which close man as a substance that can be examined, measure, and treated as an object. "Truth", "diagnosis" and "cure" are words that fit into the calculating thinking of modern science, of technique and are revealed in the parents' discourse. The therapeutic space of care allows the understanding of the child not based on a priori determinations but on what appears: the child will, then, be understood based on their meanings.

Keywords: child; psychotherapy; Caution; Heidegger.

\section{Resumen}

Partiendo de la perspectiva heideggeriana sobre el ser-ahí, presento una comprensión del niño en la contemporaneidad teniendo como hilo conductor la noción de cuidado para comprender los modos de ser del hombre en la primera fase de la vida. Fue utilizada la fenomenología como metodología cualitativa, articulando la teoría con la práctica clínica de la autora en psicología infantil. Primeramente, presento una discusión teórica sobre cuidado basado en la filosofía de Heidegger, dialogando con los autores asociados. Después, una profundización bibliográfica sobre la trayectoria histórica de las formas de relacionarse con el niño y como acumulan nuevos conceptos y patrones. Por fin, presento una perspectiva heideggeriana del ser-ahi del niño. La conducción del niño al psicoterapeuta envuelve dificultades denominadas cientificamente de "disturbios", que se refieren a la falta de ajuste a los modelos normativos constituidos en la sociedad y en la cultura. Son determinaciones históricas acerca del sentido de la experiencia infantil y constituyen el espacio en que el ser del hombre se constituye, pero es necesario pensar de qué modo este hombre está en juego en su constitución. En Heidegger, el cuidado se encuentra en la ontología de los fenómenos y precede cualquier "actitud" o "situación" vivida, es estar en juego en su existencia. El filósofo defiende que el niño pertenece a una fase cronológica del ser-ahí, no hay diferencia entre ser-ahi niño y ser-ahi adulto, e indica la inclinación actual por diagnósticos, que cierran el hombre como substancia que pueda ser examinada, medida y tratada como objeto. "Verdad", "diagnóstico" y "cura" son palabras que cuadran en el pensamiento calculista de la ciencia moderna, de la técnica, y se revelan en el discurso de los padres. El espacio terapéutico de cuidado permite la comprensión del niño no a partir de determinaciones a priori, sino en aquello que aparece: el niño será, entonces, comprendida a partir de sus propias significaciones.

Palabras clave: niño; psicoterapia; cuidado; Heidegger.

\section{Résumé}

Basés sur la perspective heideggerienne de l,Être-là, je présente une compréhension de l>enfant dans la contemporanéité. Comme fil conducteur, la notion de soins pour comprendre les manières d’être de l’homme dans le cycle initial de la vie. J`ai utilisé la phénoménologie comme méthodologie qualitative, en liant la théorie à la pratique clinique de l>auteur en psychothérapie de l>enfant. Tout d>abord, je présente une discussion théorique sur les soins basée sur la philosophie de Heidegger. Cela a été fait en dialoguant avec des auteurs qui partagent des idées semblables. Ensuite, on présente une analyse bibliographique sur le parcours historique des manières de se rattacher à l>enfant et comment ils accumulent de nouveaux concepts et modèles. Enfin, je présente une perspective heideggerienne de l>Être-là de l>enfant. Emmener l>enfant chez le psychothérapeute comporte des difficultés appelées scientifiquement " troubles 》. Ils renvoient au non-ajustement aux modèles normatifs constitués dans la société et la culture. Ce sont des déterminations historiques sur le sens de l>expérience enfantine et constituent l>espace dans lequel se constitue l’être de l>homme, mais il faut réfléchir à la manière dont cet homme est en jeu dans sa constitution. Chez Heidegger, le soin se retrouve dans l>ontologie des phénomènes et précède nıimporte quelle " attitude » ou « situation » vécue. C〉est-à-dire, il s>agit d〉être en jeu dans sa propre existence. Ce philosophe défend que l>enfant appartient à une phase chronologique de l,Être-là. Il nıy a pas de différenciation entre l, Être-là enfant ou être-là adulte, et il indique la tendance actuelle aux diagnostics, lesquels ferment l>homme comme une substance qui peut être examinée, mesurée et traitée comme un objet. «Vérité», «diagnostic» et «remède» sont des mots qui s>intègrent dans la pensée calculatrice de la science et de la technologie moderne et sont révélés dans le discours des parents. L〉espace thérapeutique du soin permet la compréhension de lıenfant non pas à partir de déterminations préalables, mais dans ce qui apparaît : l’enfant sera, alors, compris à partir de ses propres significations.

Mots-clés : enfant ; psychothérapie ; soins ; Heidegger.

O presente artigo visa apresentar fundamentos da fenomenologia hermenêtica que permitem discutir as demandas na psicoterapia infantil experimentadas na prática da autora. Trata-se de poder lançar no contexto psicoterapêutico uma 
visada à criança, não mais a partir das perspectivas sedimentadas historicamente, mas sim através do prisma da Psicologia Fenomenológico-Existencial, inspirada, principalmente, na ontologia heideggeriana, a qual concebe a criança como ser-nomundo, indeterminada e lançada ao poder-ser.

Acreditamos que as pontuações da fenomenologia hermenêutica permitem pensar em uma proposta para a psicologia clínica, na qual a criança é vista como um existente, portanto, em abertura a todas as possibilidades que se lhe apresentam, e não mais determinada como um momento especial que deve ser conduzido de acordo com um método, que implica em controle e certezas de um futuro garantido. A criança aqui precisa ser compreendida como abertura, a partir do horizonte da técnica, no qual criança e terapeuta se encontram.

No mundo contemporâneo, as concepções de infância e criança representam conceitos, teorias e técnicas fundamentados sob o prisma da ciência moderna. As concepções embasadas em teorias determinantes apresentam dificuldades de chegar ao fenômeno tal qual ele se mostra em seu campo de mostração. A dificuldade se apresenta pois, para chegar ao fenômeno, deve-se suspender as hipostasias e teorias pré-existentes, ou seja, assumir frente ao fenômeno uma atitude antinatural. Assim, seguindo a fenomenologia ontológica, a visada atravessada por preconceitos, valores e opiniões anteriores perde de vista o fenômeno.

Para exemplificar essa fidelidade ao fenômeno, Boss (1988) descreve uma macieira em flor que floresce para aquele que está diante da florescência, quem está testemunhando a árvore em flor. A florescência enquanto fenômeno pode ser acompanhada por aquele que está defronte a arvore no momento em que ela floresce (Boss, 1988, p. 58). Esse é o fenômeno em seu desvelar. Assim, para acompanhar uma criança em psicoterapia é preciso estar aberto ao modo de ser daquela criança no espaço psicoterapêutico, acompanhando serenamente e testemunhando suas ações e expressões para, a partir de então, construir com ela um caminho de cuidado e construção de sentido.

A posição fenomenológica defendida por Heidegger, na ilustração descrita por Boss (1988), traz consigo um novo modo de pensar a árvore, em que ela é vista tal qual se mostra e não é tomada como um conceito estabelecido aprioristicamente sobre árvores de uma maneira geral, mas sim ao modo de uma árvore em flor, a qual está diante de um grupo, tornando-se um fenômeno singular.

A criança, desde a sua concepção, está inserida no mundo, ainda se apropriando de seu círculo hermenêutico, com seus valores, princípios e conceitos, ou seja, com as orientações sedimentadas do mundo. Da mesma forma como esses foram sedimentados em um horizonte histórico, a criança precisa viver e con-viver com aquilo que a envolve, inclusive a história, para conhecê-la, absorvê-la e comportar-se de acordo com as orientações sedimentadas do mundo, ou seja, os moldes da sociedade, tal como é solicitada. Essa ideia é corroborada por Heidegger (2008) como uma tese fundamental sobre o ser-aí ${ }^{1}$ infantil, em que "o que está em questão é um ser-aí humano, encontra-se na base desse ser-aí humano um caráter essencialmente histórico, ainda que simplesmente não reconheçamos esse caráter” (Heidegger, 2008, p. 130).

Família e escola trazem em seu bojo as compreensões prévias do horizonte histórico no qual se encontram. Qualquer expressão da criança que não se adeque aos padrões estabelecidos pela instituição escolar, pela família ou pela cultura faz com que ela seja encaminhada a um profissional que possa devolvê-la à "normalidade" exigida, para que ela possa crescer devidamente, ou seja, adequar-se aos referenciais normatizados pelo mundo (Coimbra, 1995; Mattar, 2015). Os motivos contemporâneos que muitas vezes levam a criança à psicoterapia envolvem dificuldades denominadas pela ciência de "distúrbios", os quais se referem ao não ajustamento ao modelo proposto pela sociedade contemporânea. Na clínica psicológica essa questão aparece como queixa da dificuldade dos pais na relação com os filhos. O psicoterapeuta, nessas situações, pode ser colocado num lugar de salvador da situação familiar, situação que exige cautela do profissional para que não aceite esse lugar.

Os pais constroem, na maioria das vezes, um projeto para o percurso de vida dos filhos. Percurso este que não está no seu controle, nem depende da sua vontade. É aí que a figura do psicoterapeuta moderno aparece como aquele que deverá conhecer e introduzir um método que garanta a realização do projeto dos pais. O psicoterapeuta torna-se, para esses pais, um meio para atingir um fim.

Ameaças e obstáculos antepostos à concretização do projeto dos pais, com relação ao futuro idealizado para seu filho, por vezes, os levam a buscar psicoterapia para que nada interfira no caminho por eles idealizado. Por vezes, levar a criança para um especialista em psicologia é o máximo que os pais podem fazer para que seu projeto não fracasse. O investimento em psicoterapia por parte dos pais, por vezes, está baseado num projeto para a vida que ali se inicia. A ideia de fracasso, para aquele pequeno ser, não é considerada.

Enquanto ser-no-mundo, a criança mostra-se, desde sempre, tal qual ela aparece em seu campo de mostração, mesmo que o Dasein - aquele ser que se encontra no círculo hermenêutico com ela - não se dê conta de tal desvelamento (o apreenda faticamente). "Ser-ai é comunicar participando, descerrando, descobrindo e, desse modo, trazendo consigo" (Heidegger, 2008, p. 137).

$\overline{1}$ No presente texto está sendo utilizado de modo equivalente o termo Dasein no original e suas traduções para o português, ser-ai e pre-sença. 
Para Heidegger (2005a), nascer, crescer e morrer fala do caráter de ter-de-ser, ou seja, do cuidado² (Sörge). Para exemplificar a noção de cuidado, o filósofo recorre à fábula de Higino, a ser apresentada no decorrer deste artigo. A visada aqui pretendida é, portanto, seguir o exemplo de Saturno, descrito na fábula, compreendendo o período inicial da vida tal como ele se apresenta e, assim, permitir que ele se desvele tal como ele acontece, podendo então reconhecê-lo como qualquer outro da existência em que a vulnerabilidade está sempre presente.

No presente artigo, utilizando a hermenêutica como prática interpretativa bibliográfica, é realizado um breve percurso histórico das formas de se relacionar com a criança ao longo do tempo, apresentando como a criança vai acumulando novos conceitos e padrões. Em seguida, é feita uma discussão teórica sobre cuidado, ser-em e angústia, para, num terceiro momento, articular com as reflexões sobre a prática clínica da autora com crianças em psicoterapia.

\section{Considerações Históricas sobre a Criança}

A criança inicia seu desenvolvimento desvelando os significados do mundo em que ela está. Desde sempre, ela é ser-nomundo e, por não poder ser diferente dos outros seres que existem no modo de ser do Dasein, também é ser-para-a-morte. Nesse sentido - também desde sempre -, se reconhece na condição de finitude da existência. De início, tentando elaborar o tema consigo mesma e, quando se percebe limitada, volta-se àquele a quem ela acredita saber: o adulto. A forma de reagir do adulto pode auxiliar a criança nesse desvelamento ou pode dificultá-lo, tentando ocultar um tema que ele também ainda não é capaz de elaborar (Yalom, 1980). Heidegger (2008) a esse respeito complementa: "segundo a sua essência, o desvelamento do ente por si subsistente é algo que o ser-aí compartilha com o ser-aí, podendo um outro ser-aí estar presente faticamente ou não e podendo ele se apropriar faticamente da verdade ou não." (Heidegger, 2008, p. 136).

A palavra infância foi construída e sistematizada historicamente e significa abertura e ausência de fala (Angerami, 2004), o que coloca a criança no lugar daquele que não é detentor do discurso de si. É fato que, em todas as épocas, as pessoas nascem pequenas, não totalmente desenvolvidas, e crescem, desenvolvendo-se com o tempo, mas só a partir do século XVI, e amplamente no século XVIII (Del Priore, 2002), surge a ideia de infância, que parece acontecer mais por uma necessidade social e econômica do que por qualquer outro motivo.

A preocupação com a fragilidade infantil, que, na Idade Média, era tomada como natural, sendo a morte esperada, tem seu início no Renascimento. Segundo Veyne (2009), no Império Romano, as crianças eram apenas números e poderiam ser amplamente utilizadas como escravos, caso enjeitadas por sua família. A sobrevivência da criança passa a ser mais valorizada a partir do Renascimento, quando a morte da criança passa a ser socialmente evitada. Com a aceleração do desenvolvimento político e econômico mundial, busca-se também a certeza de que o curso de vida não será interrompido.

Segundo Ariès (1978), é também na Idade Média que "as idades da vida" adquirem uma importância de correlação com a vida prática. Tais idades indicavam períodos da vida, como infância e puerilidade, juventude e adolescência, velhice e senilidade, nomeações que foram, com o passar dos tempos, adotadas para abstrações, como puerilidade ou senilidade (Ariès, 1978, p. 33).

Antes do século XV, além das escolas latinas, as crianças poderiam seguir os meninos mais velhos "partilhando sua vida na alegria ou na desgraça". A convivência com seus companheiros era reguladora da sua vida cotidiana e tinha um valor moral (Ariès, 1978, pp. 178-179). Com o fim da Idade Média, o modelo baseado em categorias de idades diferenciadas de infância e juventude, antes relacionadas à dependência ou independência, caiu por terra, por ser considerado um movimento desordenado e anarquizado, sendo necessário ser substituído por novos princípios de comando e de hierarquia autoritária, que correspondia ao momento social e político do estabelecimento da monarquia autoritarista. Estudiosos da época procuravam difundir uma nova ideia de infância e educação, na qual se visava "formar espíritos, inculcar virtudes, educar tanto quanto instruir" (Ariès, 1978, p. 179).

As categorias de idades diferenciadas de infância e juventude, antes relacionadas à dependência ou independência, se difundiram no final do século XIX com a burguesia e o desenvolvimento das escolas e universidades. A partir desse período, iniciaram sequentes estratificações de idades, correlacionando com possibilidades de ensino para cada uma delas. Antes, as escolas mantinham o ensino com idades diferentes conjuntamente, e aos poucos foram sendo segmentadas (Ariès, 1978).

Heywood (2018) atenta para o caráter dinâmico imposto aos significados das infâncias, que são uma "construção social" que se modifica nas distintas culturas, salientando ainda para o risco de pensar em uma criança "natural e universal", com características determinadas biologicamente.

Alguns períodos históricos contribuíram para o enaltecimento do caráter individual da liberdade e responsabilidade. Assim, tanto o fracasso como o sucesso passaram a depender do indivíduo e da família. Como resultado disso, atualmente, percebe-se a ampla preocupação com o tornar-se bem-sucedido.

2 A palavra empregada por Heidegger foi Sörge, que, em latim, significa cura e, em português, cuidado. Na edição de 2005, o tradutor usa a palavra em latim. No presente trabalho, será usado o correspondente em português. 
Segundo Castro (1988), a ideia de infância, na atualidade, começa a desaparecer. O que foi considerado infância em períodos históricos do passado recente, ou melhor, no passado da modernidade, não é mais considerado atualmente. Com o domínio do capitalismo, as crianças passaram a ser inseridas num contexto de competição, individualismo, controle e superação. A antropóloga acrescenta que a infância como instância definidora do ser criança está acabando, correspondendo ao processo histórico em que nos encontramos. No entanto deixa aberta a questão da continuidade, de como as crianças estão se revelando nos dias atuais.

\section{A Ontologia do Cuidado}

A criança desde sempre é ser-no-mundo, ou seja, Dasein, tal como todos nós que existimos no modo de ser do Dasein. E, como tal, constitui-se como ser-para-a-morte. A criança assim compreendida conduzirá o desenvolvimento do Dasein da criança. São discutidos, neste artigo, o desvelar do homem no mundo, a questão do ser, o horizonte histórico, a temporalidade do ser, ou seja, o cuidado (Sörge) a partir da ontologia heideggeriana, na qual "a explicação do ser da como cuidado não força o ser da a se enquadrar numa ideia imaginada, mas nos permite conceituar existencialmente o que já se abriu de modo ôntico-existenciário" (Heidegger, 2005a, p. 262).

Em Ser e tempo (Heidegger, 2005a), Heidegger questiona o sentido do ser. O sentido do ser, segundo o autor, é a existência, a abertura de sentidos no mundo. Heidegger (2005b), em toda a sua obra, desenvolve uma linguagem que gera estranhamento, tal qual visasse eliminar qualquer correlação com significados já estabelecidos pela tradição. O sentido do ser é, portanto, Dasein, que pode ser traduzido como ser-aí, o ser aberto às coisas do mundo e às possibilidades. A tradição é considerada como todo o conjunto de ideias, conceitos, práticas e saberes estabelecidos até o momento socio-histórico, político e cultural atual, é algo que segue a atitude natural.

O Dasein - no seu modo de ser mais próprio - é o ser-em e o ser-com, ou seja, o ser-no-mundo e o ser-com os outros seres e entes do mundo. Nessa leitura ontológica, o cuidado é o próprio Dasein, o estar no mundo é o cuidado. Do mesmo modo que estar no mundo não é algo estático, o Dasein também não é: ele está em relação com o mundo, que é passível de mudanças de acordo com as necessidades do ser.

Para Heidegger, o ente ${ }^{3}$ é aquele cujo modo de ser é simplesmente dado, o qual não reflete sobre o seu estar no mundo, não questiona o seu sentido dentro do contexto, o ente; portanto, não se reduz àqueles que não são dotados de racionalidade, ou seja, animais e coisas materiais (inanimadas). O ente está privado do caráter de poder ser e pode também se revelar naquele homem que está, sem se saber, sem se compreender, ou seja, o homem, enquanto ser-no-mundo, pode se entificar.

Não no sentido oposto, mas complementar, o $\operatorname{ser}^{4}$ é aquele dotado do caráter de poder ser, é aquele que está dotado da possibilidade de questionar a sua existência, enquanto ser-no-mundo. O ser se mostra e se oculta e, ao questionar a sua existência, é capaz de compreender a si mesmo no mundo em que vive e com as coisas e pessoas à sua volta, na sua vivência. Não pode ser, em hipótese alguma, reduzido ao conceito de ente. Assim, o ser do homem não pode se revelar enquanto Dasein sem a possibilidade de questionamento do sentido do ser homem no mundo. O ente é aquilo que pode ser percebido, conceituado e generalizado. É, por vezes, estático, enquanto o ser deve ser compreendido no seu modo de ser, agir e se transformar. O ser é, em sua essência, indeterminado e indeterminante.

O ser-no-mundo já é sempre numa decadência. Pode-se, portanto, determinar a cotidianidade mediana da pre-sença como ser no mundo aberto na decadência que, lançado, se projeta e que, em seu ser junto ao 'mundo' e em seu ser-com os outros, está em jogo o seu poder ser mais próprio. (Heidegger, 2007, p. 244)

O ser-aí está lançado no mundo, está com as coisas, com as pessoas, está na história. No seu caráter mais próprio de poder ser, o Dasein está, de início, na maioria das vezes, no mundo, seguindo o curso do geral, correspondendo às demandas do mundo. Isto é denominado cotidianidade mediana, e se dá na ausência de reflexão daquilo que se experiencia, de onde se está, de para onde se vai. O homem, na cotidianidade mediana, mantém-se no impessoal: apenas vai, não importa para onde. Contudo, em seu estar lançado, o ser é capaz de, no jogo do próprio e do impróprio, apropriar-se de algo, gerando um ins-tante ${ }^{5}$ de singularização. A singularização se dá quando o ser se apropria de algo do mundo para si. Entretanto, como no ins-tante, ele retorna para o mundo e o jogo do próprio e do impróprio não cessa.

\footnotetext{
3 Ente é tudo aquilo que pode ser restringido a um significado, a um conceito; que pode ser nomeado, caracterizado, definido.

4 “(...) o ser não pode ser concebido como ente, (...) o ser não pode ser determinado, acrescentando-se um ente. Não se pode derivar o ser no sentido de uma definição a partir dos conceitos superiores e nem explicá-los através de conceitos inferiores. (...) O ser é o conceito evidente por si mesmo" (Heidegger, 2005a. p. 29).

5 Em alemão, a palavra Augenblik refere-se a, segundo o tradutor de Ser e tempo, "a visão de um piscar de olhos.” (Heidegger, 2005a, p. 260). O uso do hífen, na palavra ins-tante, visa à acentuação do sentido, imprimindo velocidade e dinâmica ao termo.
} 
A impropriedade e a propriedade ontológicas não correspondem ao certo e errado, ôntico, ou seja, ao senso comum. O ser, no modo de ser impróprio, não está olhando para sua existência, foge de si, e esse desviar-se pode se dar no modo da ocupação, em que o Dasein toma para si aquilo que no mundo vai ao encontro da apropriação do ser enquanto abertura de sentido. O modo de ser próprio, portanto, caracteriza-se pelo olhar para seu ser-no-mundo, não apenas tomando para si, mas debruçando-se sobre o que vem ao encontro, de forma atenta e singular.

Rodrigues (2006, p. 57) acrescenta que o Dasein na ocupação "fecha-se ao sentido do ser dos entes e toma para si mesmo e aos outros, como um ente cujo modo de ser é simplesmente dado; compreende-se como se seu ser estivesse determinado $a$ priori, como uma cadeira ou qualquer outro objeto material e não como um ente cujo ser está em jogo no seu próprio existir".

Em primeira instância, a noção de cuidado que se pretende descrever foge do que concebemos no senso comum, ou seja, não será tratada como "um ato em função de". O sentido com que a palavra "cuidado" é comumente utilizada, é o que Heidegger considera cuidado ôntico, o qual deriva do cuidado ontológico. A partir da hermenêutica heideggeriana, busca-se romper com aquilo que se apresenta sedimentado historicamente, do cuidado ao modo de uma vida bem-sucedida. Daí a incessante exigência de sucesso tão característica da modernidade.

Para desdobrar a noção de cuidado, Heidegger (2005a) começa por romper com a dicotomia cartesiana, ou seja, com a cisão mente e corpo, partindo da pressuposição de sua cooriginalidade. Assim, conclui que o homem se posiciona no mundo, logo, ele se encontra no mundo como mundo. Assim, lançado com apenas um privilégio, o de pensar a si mesmo, pode questionar seu modo de ser-no-mundo. Considera também a existência coexistindo com a essência e, por isso, o existente só pode ser compreendido em sua existenciaridade. Dessa forma, impossibilita pensar o cuidado como algo posicionado, estabelecendo-o como a tarefa de existir sempre remetido a algo, tendo de ser para si mesmo, para os outros Dasein e para as coisas.

O filósofo alemão orienta para que se faça essa compreensão e interpretação da maneira mais simples, em que o modo de abertura, a compreensão, é colocado diante do próprio fenômeno: o homem como Dasein se coloca diante de si, buscando a totalidade da compreensão do seu ser homem. Dessa forma, ao se relacionar de modo compreensivo, o homem é cuidado (Heidegger, 2005a).

$\mathrm{Na}$ ontologia heideggeriana, cuidado é tomado tal como posto por Higino na fábula do cuidado (Heidegger, 2005a), cujo enredo gira em torno da disputa dos seguintes personagens: Terra, Cuidado e Júpiter. Ao iniciar, Cuidado dá uma forma a uma matéria (Terra) já existente. Júpiter toma para si essa matéria com uma forma pré-estabelecida e lhe dá, a pedido de Cuidado, o espírito. Forma, matéria e espírito tornam-se coexistentes. Contudo, Cuidado, Júpiter e Terra iniciam uma disputa sobre a quem essa nova coexistência, ainda não nominada, pertenceria. Diante de tal disputa, é dada a Saturno - que estava fora da disputa - a função de decidir sobre o ente criado. Nomeando-o como Homo, Saturno determina em seguida que, enquanto viver o homem, pertencerá a Cuidado; ao morrer, seu espírito será de Júpiter e sua matéria retornará à Terra.

Certa vez, atravessando um rio "cura" viu um pedaço de terra argilosa: cogitando, tomou um pedaço e começou a lhe dar forma. Enquanto refletia sobre o que criara, interveio Júpiter. A "cura" pediu-lhe que desse espírito à forma de argila, o que fez de bom grado. Como a "cura" quis então dar seu nome ao que tinha dado forma, Júpiter a proibiu e exigiu que fosse dado o nome. Enquanto "Cura" e Júpiter disputavam sobre o nome surgiu também a "Terra" (tellus) querendo dar seu nome, uma vez que havia fornecido um pedaço de seu corpo. Os disputantes tomaram Saturno como árbitro. Saturno pronunciou a seguinte decisão, aparentemente equitativa: "Tu, Júpiter, por teres dado o espírito, deves receber na morte o espírito e tu, terra, por teres dado o corpo, deves receber o corpo. Como, porém, foi a "cura" que primeiro formou, ele deve pertencer à "cura" enquanto viver. Como, no entanto, sobre o nome há disputa, ele deve se chamar "homo", pois foi feito de húmus (terra). (Heidegger, 2005a, p. 263)

A existência se dá do nascer ao morrer, mas, enquanto existir, ao homem é destinado a ter de ser. A fábula é utilizada como uma metáfora para ilustrar o modo de pensar, o ter de ser do homem, enquanto ele é. Cuidado é, portanto, tomar para si a responsabilidade de ter de ser.

A fábula retrata que, enquanto a maquete do futuro homem era dividida em partes, ou seja, vista separadamente como forma, matéria e espírito, era um ente simplesmente dado, estático no tempo e no espaço. Ao ser lançado no mundo, tornase homem, ganha movimento, ganha a possibilidade de ser. Mais do que isso: é-lhe imposta a possibilidade de ter de ser enquanto é, ou seja, enquanto vida tiver, o homem estará no mundo compelido a fazer suas escolhas e, enquanto viver, a forma dele viver pertencerá ao cuidado. A morte representa o fim das possibilidades, e só a partir de então o homem pode ser dividido novamente, tornando-se matéria, forma e espírito, retornando para aqueles que o criaram. Portanto, investigar o homem enquanto ser no mundo é investigar o homem sob a tutela do cuidado.

O cuidado existe antes do ser por já ser e estar num mundo em relação com outros, entes dotados ou não do caráter do Dasein. Estar no mundo não é simples como designado pela tradição. No ciclo da vida, pessoas nascem, crescem, reproduzem-se e morrem, não é meramente algo mecânico, instintual ou, utilizando os termos heideggerianos, não é estar no mundo no modo impróprio. Estar no mundo envolve o viver, o apropriar-se da relação com os entes que envolvem o ser do 
ente: instinto de sobrevivência, amor, carinho, atenção, desejo, vontade, propensão, intenção, responsabilidade, ansiedade, bem como suas formas opostas e negativas. Para a ontologia heideggeriana, esses são modos ônticos do Dasein, enquanto lançado no mundo, experienciar o que está a sua volta. Isto tudo é cuidado, e cuidado é viver, estar em relação com aquilo e aqueles que estão à volta: é manter-se vivo, é esperar a morte. É preciso estar vivo para ser cuidado.

O fenômeno cuidado não pode ser desconstruído ou reconstruído em atos ou impulsos particulares como "querer ou desejar, propensão ou tendência", porque fazem parte do Dasein enquanto cuidado e constituem ontologicamente o ser. São consideradas vivências diferentes, que fazem parte da dinâmica do Dasein "como uma corrente inteiramente indeterminada quanto ao sentido de seu ser" (Heidegger, 2005a, p. 258). Eles fundam-se no cuidado, que é anterior aos fenômenos citados (Heidegger, 2005a).

O cuidado se encontra na ontologia dos fenômenos e está existencialmente precedendo qualquer "atitude" ou "situação" vivida por esse ser. Logo, o cuidado está e é toda situação e atitude de fato, o que não significa que a prática é anterior à teoria, mas que ambas são possibilidades ontológicas do Dasein.

O cuidado pode englobar o sentido do ser (Heidegger, 2005a). Pode-se dizer que ele é o viver e o viver em relação com o seu contexto, seu horizonte de sentido, compreendendo o sentido do viver e da relação que é estabelecida. Contudo cuidado é relação, é um fenômeno que se transforma de acordo com as necessidades do ser, as quais não se mostram quando o ser está fechado para as possibilidades da vida. É preciso que o ser se impulsione para essa abertura. Heidegger (2005a) diz que, para compreender o ser como cuidado, é preciso estar ciente que é a angústia que mobiliza o Dasein, que tem como privilégio o questionamento acerca do lugar do seu ser-no-mundo.

O fenômeno cuidado (Sörge) pode ser dividido em dois modos de existir: ocupação (Bersorgen) e preocupação (Füsorge). Ambos são modos de desvelamento do cuidado, sendo o primeiro o cuidado no mundo (manualidade), relacionado com o mundo dos entes simplesmente dados; o segundo, o cuidado com os seres deste mundo, que estão em relação constante com os entes que são o Dasein, abertura de sentido (Heidegger, 2005a). A ocupação é uma possível definição para o cuidar compreendida pelo senso comum, visto que o cuidar ôntico é uma ação, uma prática que se dá dentro de uma experiência e, geralmente, é precedida de um conhecimento anterior, ou seja, algo simplesmente dado. Cuidar pode ser considerado, no senso comum, uma ação com um objeto anteriormente determinado, com práticas preestabelecidas no horizonte histórico da tradição. Heidegger apresenta a ocupação e preocupação como modalidades possíveis de desvelamento do cuidado. A ocupação está ligada à manualidade. A preocupação está ligada ao todo do ser, à compreensão completa da relação que corresponde a explicar, se fazer compreender e perceber se está sendo compreendido.

Sá (2017) menciona que a preocupação pode surgir na relação de dois modos. O primeiro é a preocupação como substituição (Einspring), que é caracterizada pelo domínio de um ser sobre o outro, ou seja, em que um ser assume as ocupações do outro, transformando-as em algo que não precisa mais de reflexão. No segundo, a preocupação é anteposição, ou seja, ao invés de substituir, orienta o ser em um caminho de reflexão diante de si e de suas possibilidades como existente. Esta última seria o cuidado, revelando-se ao seu modo de ser mais próprio, como teorizou Heidegger. Contudo substituição e anteposição são possibilidades e podem se mostrar mescladas no cotidiano do ser.

\section{Fenomenologia e Hermenêutica}

Ao questionar sobre o modo de ser do homem e sobre como se dá o conhecer daquilo que lhe vem ao encontro, Heidegger, em Ser e tempo (2005a), com base na fenomenologia de Husserl, defende que, para se investigar o modo de ser do homem, tem-se que ir "às coisas mesmas" e, para tanto, é necessário suspender os conceitos pré-estabelecidos, seja subjetivamente, seja culturalmente. O filósofo alemão pretende - seguindo, a princípio, o caminho husserliano, chegar à essência das coisas. Em sua principal obra, Ser e tempo (Heidegger, 2005a), desenvolveu a analítica do Dasein na busca de responder à questão: "Qual o sentido de ser?"

(...) a totalidade do todo estrutural não pode ser alcançada fenomenalmente mediante a uma montagem de elementos. Para isso seria necessário um plano. O ser da pre-sença, que sustenta ontologicamente o todo estrutural, torna-se acessível num olhar completo que perpassa esse todo no sentido de um fenômeno originariamente unitário, que já se dá no todo, de modo a fundar ontologicamente cada momento estrutural de possibilidade. A questão do caráter do ser difere essencialmente do ser de algo simplesmente dado. (Heidegger, 2005a, p. 244)

A busca pelas “coisas mesmas” se inspira no seu precursor Edmund Husserl, que defendia a epoché para, então, poder ir às "coisas mesmas", nisto consistindo seu método: suspensão de valores, princípios e teorias objetivantes.

À fenomenologia, Heidegger acrescenta a hermenêutica, como a arte de interpretar a partir da compreensão da historicidade do fenômeno. Heiddeger busca o sentido de hermenêutica em sua originalidade, ou seja, na Grécia antiga, que foi personificada na mitologia no deus Hermes. A este deus grego de asas nos pés cabia, além de diversos atributos, ser 
mensageiro dos deuses, sendo o único que podia transitar livremente entre o Olimpo (terra dos deuses), a Terra dos Homens e o Reino de Hades, podendo levar e trazer mensagens entre os deuses e os homens. Hermes era o único com o dom de traduzir as mensagens dos deuses para que elas fossem compreendidas pelos homens.

A compreensão do fenômeno se dá a partir da apresentação do fenômeno tal como ele se apresenta. Isso significa compreender também o campo hermenêutico, ou seja, dar-se conta do horizonte histórico no qual o fenômeno se desvela. Rodrigues (2006) argumenta que o caráter de estranhar o fenômeno torna-se fundamental no exercício da fenomenologia. Ao escapar da estranheza, retorna-se ao espaço considerado seguro, no qual o fenômeno está referenciado a conceitos e ideias sedimentados historicamente. No lugar considerado seguro perde-se o fenômeno enquanto tal. A proposta de Rodrigues (2006) consiste em, a partir da ontologia heideggeriana, questionar o lugar de segurança que, na contemporaneidade, atrelase a um objetivo a ser alcançado a qualquer preço.

\section{A Estrutura do Dasein: ser-em}

Nesse ponto, torna-se importante entender como acontece a compreensão que em seu desdobramento se constitui como interpretação. Segundo Rodrigues (2006), para o filósofo alemão, a compreensão faz parte da estrutura ontológica do Dasein, é a existenciaridade o fator determinante do Dasein. Dessa forma, a compreensão é um existencial. Os existenciais não podem ser considerados como categorias que determinam ontologicamente os entes que são desprovidos da possibilidade de poder-ser, são entes simplesmente dados. Pensar a compreensão como um existencial é tomá-la como constitutiva do ser que existe, deixando de lado a noção de compreensão como cognição, ou seja, faculdade que pode ser desenvolvida, estimulada, podendo ocorrer ou não.

Ainda segundo Rodrigues (2006, p. 156), Heidegger considera a compreensão como abertura de sentido, visto que Dasein compreende o mundo, com seus sentidos, possibilidades e determinações. Rodrigues complementa que "é exatamente esta abertura que permite todas as formas de 'compreensões' subsequentes, conforme o termo é compreendido no senso comum".

O homem enquanto abertura de sentido, ou seja, Dasein, é o único entre os entes com a possibilidade de compreender mundo. $\mathrm{O}$ ente simplesmente dado não compreende mundo, ou seja, uma pedra, um giz ou uma cadeira não pensam sobre o sentido do estar no mundo, não compreendem, tampouco interpretam. A interpretação, por sua vez, é possível num segundo momento, ou seja, posteriormente à compreensão, pois é nela que consiste a possibilidade de tematizar, meditar e elaborar sobre as possibilidades anteriormente compreendidas.

Heidegger afirma que toda compreensão e a consequente interpretação estão sintonizadas com o humor, não sendo, portanto, algo que se dê, simplesmente, no plano intelectivo, estando sempre impregnadas de certo quantum afetivo, uma afinação. (Rodrigues, 2006, p. 58).

Com essa base, a compreensão e a interpretação no mundo se dão a partir do próprio fenômeno. Rodrigues (2006, p. 59) complementa: "o discurso está na palavra, no silêncio, na escuta, na leitura, no sonho, ou seja, em todas as formas de expressão do ser no mundo".

\section{Sobre a Angústia}

A angústia, para Heidegger, é inerente à existência humana, não é algo simplesmente dado, é um existencial, ou seja, condição de possibilidade do Dasein, que permite ao ser descortinar o horizonte ôntico e explicar a própria existência como ente. Ao experienciar a angústia, o ser-do-homem se coloca diante de si a partir do seu próprio ser. Essa mudança de posição permite ao Dasein se responsabilizar (ter de ser) pelo que pode acontecer a partir de então: estabelece-se uma relação de cuidado consigo mesmo.

A todo o momento, o Dasein foge do seu poder ser mais próprio ao se manter no mundo das ocupações. Este, na verdade, mostra-se como o solo menos propício para investigar a possibilidade de determinar a essência do Dasein, contudo, fugir de si só é possível após o encontro consigo, ou seja, ao estar lançado no mundo o ser coloca em prática o jogo do próprio e do impróprio. Esse jogo é um permanente movimento do ser no sentido de fuga da angústia, e no in-stante seguinte isso pode se inverter, pois "é justamente daquilo que se foge que o Dasein corre atrás" (Heidegger, 2005a, p. 247). Mesmo diante dessa fuga incessante, algo fica. Torna-se possível apreender aquilo de que se foge como tal.

Com a angústia, o Dasein se abre para o questionamento do sentido de ser, podendo - a partir da angústia - perceber-se diferente dos outros seres, ou seja, a angústia abre a possibilidade da singularização, ser a si próprio e saber diferenciar-se dos demais seres no mundo que o circunda. Ao perceber-se diferente, segundo Heidegger, o ser não se perde nas coisas do mundo, não fecha as possibilidades. A singularização retira o ser do lugar de imobilidade diante do mundo para um lugar de escolha. Esse lugar, contudo, mantém o ser na angústia: "Em sua completude, o fenômeno da angústia mostra, portanto, a pre-sença como ser-no-mundo que de fato existe" (Heidegger, 2005a, p. 255). 
O ser, para se compreender sendo no mundo, deve se questionar, explorar suas questões, deve ser alavancado pela angústia para que o fenômeno de compreensão seja completo, e, paradoxalmente, não se compreenda totalmente, para que se reconheça aberto a novas possibilidades. Isto caracteriza o poder ser, que não necessariamente é que o ser esteja sempre no seu modo de ser próprio, mas que se reconheça na abertura de poder ser próprio e impróprio. A propriedade do viés ontológico é: “em seu ser a pre-sença já sempre precedeu a si mesma” (Heidegger, 2005a, p. 256).

Para buscar o sentido do ser é preciso ir à medianidade cotidiana (Heidegger, 2005a). O Dasein se revela nos modos de ser-em e ser-com, ou seja, o ser-no-mundo e o ser com os outros seres e entes do mundo e, no seu modo de ser mais próprio, o ser-para-a-morte. O Dasein é modo de ser da abertura das possibilidades e a morte indica o fim dessas possibilidades enquanto ser-no-mundo.

De início e, na maioria das vezes, o ser-aí encontra-se no mundo ao modo da impessoalidade. Isto pode ser descrito diante da ideia da atemporalidade, em que o ser acredita que estará no mundo eternamente. Tal ideia amplia as possibilidades, faz com que, de forma imprópria, o homem acredite ser capaz de escolher todas as opções disponíveis. No entanto o Dasein é temporal, é passado, é presente e é futuro. Como ser-no-mundo, já é desde sempre ser-para-a-morte.

Na perspectiva contemporânea, a criança, mesmo sendo no mundo, é muitas vezes tomada como eterna. É fato que ela está iniciando seu curso de vida no mundo, entretanto não existem certezas de que esse curso será longo ou que será de sucesso. A vida é o caminho para a morte, porém essa afirmação torna-se, muitas vezes, insustentável na experiência da vida do homemno-mundo. Gera angústia. As escolhas tornam-se angustiantes; saber-se temporal, finito, leva o ser ao seu próprio encontro.

O Dasein criança está lançado no mundo com os outros Dasein e entes. Está no jogo incessante do próprio e impróprio, tendo como determinante o caráter do ter de ser e ser-para-a-morte. Desde o seu nascimento, a criança necessita de auxílio, suporte para que possa crescer e seguir o rumo próprio da sua vida. É fato a necessidade de um adulto, um Dasein para orientar e proteger esse Dasein no período inicial da vida, que faz com que as necessidades cotidianas, fisiológicas ou psicológicas da criança sejam atendidas. Tal adulto pode ser o pai, a mãe ou algum outro familiar. Porém, na contemporaneidade, muitas vezes, além de suprir as necessidades na medida do possível, não interrompe a sua participação nesse ponto, passando a se ocupar das escolhas e do futuro da criança, preocupando-se de que boas escolhas trazem um futuro certo, positivo e bem-sucedido. Ele se cerca também, no seu horizonte histórico, da certeza de que pode tomar para si o cuidado, no sentido ôntico, da criança que está sob sua tutela. Os responsáveis passam a se mostrar no modo de ser do cuidado substitutivo na relação com a criança.

\section{O ser-aí Criança: Considerações Heideggerianas}

Na sociedade moderna, a criança é descrita como algo de caráter especial, que necessita de cuidados diferenciados para percorrer o longo caminho da vida. Tal descrição encontra-se repleta de conceitos, teorias e técnicas, e os olhares atravessam primeiro o que já foi visto, dito e escrito, direcionando os caminhos que a criança deverá traçar. No desenrolar do percurso histórico, a criança e suas relações são atravessadas pelo horizonte histórico da época, de modo que se percebe que a etapa de vida que denominamos como infância vem sendo sistematizada histórica e teoricamente, baseada no pensamento da técnica moderna.

As determinações históricas acerca do sentido da experiência infantil, sem dúvida, constituem o espaço em que o ser do homem se constitui. No entanto é preciso pensar de que modo esse homem está em jogo em sua constituição. Para uma hermenêutica da situação da constituição da infância que considera o caráter de historicidade sem abandonar como a existência se constitui a partir de sua indeterminação originária, busca-se elementos para essa discussão na fenomenologia hermenêutica de Martin Heidegger.

Em Heidegger, as interpretações históricas ganham outra perspectiva. Para ele, antes de tudo, para se pensar na criança é preciso partir da ideia de que, desde o início, a criança é esse ente que tem o caráter de indeterminado. A criança é a denominação de uma etapa da vida do homem, pertence a uma fase cronológica daquele que tem o modo de ser do Dasein. Desse modo, não há diferenciação entra ser-aí criança ou ser-aí adulto. Dasein criança é, antes de tudo, o próprio Dasein, e pelo caráter de ser-aí não difere de nenhum outro Dasein, seja o do homem primitivo, seja o do homem moderno. Como serno-mundo se constitui não a partir de si mesmo, mas em um horizonte histórico do qual e no qual o Dasein sempre se constitui.

Segundo Heidegger (2008), atualmente, estão disponíveis diversas formas de interpretar o Dasein, como as perspectivas psicológicas tradicionais, psicanalista, antropológica e etnológica, que devem ser analisadas com cautela. Heidegger parte do princípio de que o Dasein infantil é um Dasein humano e tem em sua base um caráter histórico em sua essência, mesmo que, por vezes, não seja reconhecido (Heidegger, 2008).

A família, a escola ou o bairro onde moramos trazem em si mesmos compreensões prévias do horizonte histórico em que nos encontramos, ou seja, cada Dasein constitui o mundo a partir de um horizonte de sentido previamente compreendido. É a partir do seu horizonte histórico que o homem em toda a sua existência pode desenvolver formas de se articular com situações-limite. Brincar, jogar e movimentar-se são formas da criança se relacionar no mundo. 
Há poucos textos na literatura desse filósofo voltados à fase inicial da vida do Dasein, da criança. Heidegger pouco desenvolveu sobre o nascimento e muito acentuou o fato do Dasein ser-para-a-morte, justificando que, na trajetória da experiência da vida, o nascimento, como acontecimento, toma um lugar anterior a qualquer outro: o ponto de partida tornase, então, o lugar que está mais longe da experiência atual do ser-no-mundo (Heidegger, 2008).

Heidegger (2008) levanta o questionamento sobre a interpretação da infância: será que isso não acontece para atender às necessidades psicológicas ou pedagógicas de encerrar o Dasein infantil em determinada caracterização? Aponta para a inclinação atual da busca por um diagnóstico, algo que feche o homem em uma substância que possa ser examinada, medida e tratada, baseado em algo pré-estabelecido.

O autor alemão refere-se ao comportamento das crianças, em seu primeiro contato com o mundo, de uma forma diferente do modo tradicional de pensar o desenvolvimento infantil. Ele pontua que o choro ou a agitação, por menos que indique alguma finalidade, significa "estar-direcionado para fora de..." (Heidegger, 2008, p. 131), ou seja, significa abertura. Interpretar a criança como algo pré-determinado, falar de um Dasein infantil que pode ser encerrado em si mesmo, é um pensamento equivocado na perspectiva heideggeriana, visto que Dasein é abertura de sentido. O Dasein é caracterizado pela possibilidade de poder ser, e o poder ser acontece de modo ocasional e posterior, pois "( . . .) o ser-aí é, na medida em que existe como ser-aí, na medida em que é desvelado como tal” (Heidegger, 2008, p. 136). De forma nenhuma o poder ser se dá de forma pré-determinada.

Heidegger (2008) coloca que o choro é um choque, um susto, ou seja, uma reação sensível a algo no mundo que vem ao seu encontro. A criança sente-se perturbada e esse comportamento desvela "uma forma originária do deter-se e reparar em algo". É algo inerente ao deixar ser. O filósofo acrescenta ainda que:

A essência do choque só pode ser esclarecida em conexão com o fenômeno do susto e do medo. O choque significa que o encontrar-se em uma disposição de ânimo é perturbado, que entra em cena um desconforto, que deverá ser repelido. (Heidegger, 2008, p. 131)

Assim, na perspectiva heideggeriana, a criança não é algo fechado em si mesmo que, repentinamente, diante de um fenômeno pré-estabelecido, será trazido para fora. Desde sempre, a criança é Dasein - lançada no mundo, para o mundo e com o mundo. Por vezes, a criança revela formas de se comportar diante dos seres, do mundo e dos entes consideradas, pelo senso comum, como negativas, como a aversão, a defesa, a quietude e o sono. Contudo tais formas estão preenchidas de intencionalidade, que revela seu primeiro momento de entrega ao mundo (Heidegger, 2008).

\section{A Psicoterapia Infantil sob o Viés da Fenomenologia Hermenêutica}

A perspectiva da fenomenologia hermenêutica permite que as situações que demandam a psicoterapia infantil sejam desveladas ôntico e ontologicamente. A visão ôntica possibilita a visualização de como os modos de se relacionar com as crianças acontecem a partir de pressupostos já estabelecidos previamente no existir, para então, na ontológica, poder descrever, a partir de um referencial, onde essência e existência são coexistentes. A visão ontológica, a partir do pensamento heideggeriano, conduz a uma nova forma de estar no mundo e com os outros. A Psicologia Fenomenológico-Existencial se abre a esse modo de pensar e agir, propiciando um novo olhar diante do fenômeno da psicoterapia infantil.

A criança é um ser-no-mundo, portanto, é denominada de Dasein. A criança é Dasein, a criança é cuidado. No decorrer da História, perceberam-se diversos modos de se relacionar com a criança: ao modo da indiferença, ao modo da instrumentalidade, ao modo da proteção, ao modo da substituição, ao modo da antecipação. Todas essas formas são cuidado.

A criança está em pleno desenvolvimento físico, emocional e social: está crescendo. Lançada no mundo, a criança está em contato com os outros seres e entes, podendo, ou melhor, tendo que dar sentido à sua experiência. Percebe-se, então, que mesmo crianças que vivenciaram o mesmo período cultural e econômico têm na sua singularidade modos próprios de agir, pensar e estar com os outros, não sendo totalmente iguais. Todas estão inseridas no mesmo horizonte histórico e diante das demandas da técnica moderna, cada criança pode se apropriar daquilo que lhe é mais próprio. Essa apropriação, por vezes, ocorre de formas consideradas não comuns para a família, escola ou para o senso comum. Assim, a criança é encaminhada ao psicoterapeuta para restabelecer o que era antes ou, quem sabe, ficar melhor. Contudo cabe ao psicoterapeuta um olhar atento, desembaraçado, hermenêutico, para que o fenômeno da criança possa ser desvelado e ela e sua- família possam apropriar-se do que lhes pertence, compreendendo que existe um modelo proposto pela sociedade - geralmente idealizado - e a existência da criança com todas as singularidades que lhe são próprias.

Um modelo preestabelecido, com conceitos, pressupostos, normas, não cabe na criança. Não é possível moldar aquilo que não pode ser determinado - um modelo apriorístico não cabe no Dasein. Portanto, não cabe ao psicoterapeuta infantil da abordagem fenomenológico-existencial recorrer a manuais sobre comportamento, sobre desenvolvimento emocional. 
Na perspectiva heideggeriana, a criança não é algo fechado em si mesmo que, repentinamente, diante de um fenômeno preestabelecido, será trazida para fora. Desde sempre, a criança é Dasein lançada no mundo, para o mundo e com o mundo.

A pesquisa a partir do pensamento de Heidegger exige dedicação, rigor e fidelidade no estudo e na produção literária sobre o assunto. A prática em psicoterapia consiste na liberdade de ser-com-outro a partir do próprio outro. Na psicoterapia, o outro é o fenômeno e a ele são destinados a dedicação, a fidelidade e o rigor, no sentido de o psicoterapeuta manter-se sempre aberto ao seu desvelar. Tal movimento simples do psicoterapeuta pode, por vezes, parecer difícil de ser exercido, pois, desde a sua formação, o psicoterapeuta está inserido numa atmosfera em que a tradição cartesiana, a ciência e a técnica moderna reinam. Reinam com o modo de pensar causa-consequência, nexo-causal, ou seja, através do senso comum, da demanda cotidiana pelo resultado, pelo diagnóstico, pelas informações precisas, seguras e exatas. Mas a psicologia, na sua essência, não poderia comungar com tais preceitos. O objeto de estudo da psicologia é o homem e suas relações no mundo, conjunto determinado pela subjetividade impassível de ser objetivo.

A psicologia, enquanto ciência, busca determinar o indeterminável e, para ser reconhecida como ciência, necessitou enquadrar-se nesse sistema, objetivando o impossível de ser tomado como objeto: o homem. Segundo Heidegger (1959, p. 52), "a calculabilidade é uma consequência da legalidade. De tudo o que é só se considera aquilo que é mensurável, quantificável. Dispensam-se todas as outras características das coisas”.

Os motivos contemporâneos que, muitas vezes, levam a criança à psicoterapia envolvem dificuldades e ameaças ou obstáculos à concretização do projeto dos pais. Alguns obstáculos são denominados pela ciência de distúrbios, que se referem ao não ajustamento ao modelo proposto pela sociedade atual. Portanto, a "normalidade" exigida também está orientada pelo mesmo horizonte da criança. Levar uma criança para psicoterapia, por vezes, é o máximo que os pais conseguem fazer para que seu ideal de futuro para seu filho não fracasse.

A busca por respostas exatas é um movimento comum dos pais que procuram por um psicoterapeuta infantil. Entretanto trazem consigo um diagnóstico já estabelecido e a psicoterapia torna-se, muitas vezes, um método seguro e controlado por meio do qual será realizado o projeto criado para a vida que ali se inicia. O especialista torna-se um meio para um determinado fim; o psicoterapeuta infantil torna-se esse meio que garantirá o sucesso do projeto.

"Verdade", "diagnóstico", "cura": todas são palavras que se encaixam no pensamento calculante da ciência moderna, da técnica e se revelam do discurso dos pais em forma de perguntas, como: "Meu filho vai melhorar, doutora?", "Quando?", "Isso tem cura?", "Eu quero a verdade, hein!".

A atitude dos pais aponta para uma atitude natural diante do fenômeno, tirando conclusões acerca do comportamento dos filhos. Apontando para o modo de pensar contemporâneo da busca incessante por um diagnóstico, algo que possa ser examinado, medido e tratado baseado em algo preestabelecido. Na perspectiva fenomenológico-existencial e hermenêutica, o psicoterapeuta caminha na direção oposta, não devendo se guiar pela atitude natural, e sim por um modo de pensar pautado na atitude antinatural. Assim, a partir do processo psicoterapêutico, os pais podem apropriar-se do movimento que é realizado para alcançar seus objetivos e metas, tornando-se abertos para um deixar acontecer de si e da criança, abrindo-se para o que Heidegger chama de projeto originário. Investiga-se o período inicial da vida tal como ele se apresenta e, assim, permite-se que ele se desvele tal como ele acontece, podendo então reconhecê-lo como qualquer outro da existência em que a vulnerabilidade está sempre presente.

O psicoterapeuta orientado pela perspectiva fenomenológico-existencial deve acompanhar o caminhar da criança no seu próprio círculo hermenêutico, trazendo à abertura aquilo que se mostra e mantendo essa abertura para o desvelamento do caminho da criança. A criança atua no mundo para brincar, para se comunicar, expressar suas inquietações, seus medos e seus desejos. Permitir à criança brincar e estimular seu pensamento mágico faz com que elabore as situações que são conflitantes para ela no seu mundo a partir do seu horizonte de sentido. A compreensão da criança não está naquilo que corresponde a suas experiências internas, das quais ela não pode saber ou não quer falar a ninguém. Pelo contrário, está naquilo que aparece: a criança será, então, compreendida a partir das suas próprias significações (Cytrynowicz, 2000).

\section{Ideias Conclusivas}

Com Heidegger (2005a), pode-se conhecer a fenomenologia hermenêutica, que permite àquele que observa o fenômeno a compreensão do que se mostra, tal qual ele se mostra. A hermenêtica, enquanto arte de interpretar, permite ao observador que observe com os olhos, ou seja, mudando sua postura para a, se desvencilhando da dicotomia sujeito e objeto. Observar com os olhos é estar presente, ater-se àquilo que está diante das pupilas e demorar-se.

A noção de cuidado heideggeriana escapa do senso comum, ou seja, não é "um ato em função de". O cuidado se encontra na ontologia dos fenômenos e está existencialmente precedendo qualquer "atitude" ou "situação" vivida por esse ser. Logo, o cuidado está e é toda situação e atitude de fato, o que não significa que a prática é anterior à teoria, mas que ambas são possibilidades ontológicas do Dasein. 
Heidegger (2005a) apresenta a ocupação e preocupação como modalidades de desvelamento do cuidado. A ocupação está ligada à manualidade. A preocupação está ligada ao todo do ser, à compreensão completa da relação que corresponde a explicar, se fazer compreender e perceber se está sendo compreendido. O adulto (pai, mãe ou responsável) passa a se ocupar das escolhas e do futuro da criança, preocupando-se com que boas escolhas tragam um futuro certo, positivo e bem-sucedido. Ele se cerca também, no seu horizonte histórico, da certeza de que pode tomar para si o cuidado, no sentido ôntico, da criança que está sob sua tutela. Os responsáveis passam a se mostrar no modo de ser do cuidado substitutivo na relação com a criança.

Percebe-se, então, a importância de abrir um espaço de acolhimento e estar disponível àquilo que está para acontecer. Acolher os sentimentos da criança e descrever claramente sobre os possíveis caminhos da psicoterapia é um modo de cuidado. A Psicologia Fenomenológico-Existencial oferece um espaço de escuta para crianças e pais, no qual eles podem ressignificar aquilo que lhes gera sofrimento.

Vale ressaltar que o psicoterapeuta orientado pela postura antinatural do pensamento heideggeriano não tem como objetivo abarcar ou solucionar a demanda dos pais de modo exógeno (algo imposto de fora), mas sim permitir que se questionem diante das possibilidades dos seus filhos, abrindo um espaço em que pais e crianças possam estar presentes diante de seu sofrimento e, a partir de então, se debruçar sobre as possibilidades. Disponíveis uns aos outros, pais e criança, com o psicoterapeuta, podem se compreender a partir do modo de ser mais próprio de cada horizonte de sentido.

Acredita-se que a discussão aqui apresentada tenha permitido uma articulação entre a Psicologia FenomenológicoExistencial, a perspectiva heideggeriana e a prática da psicoterapia infantil. Nota-se que demandas destinadas ao psicoterapeuta se mostraram coerentes com o horizonte histórico contemporâneo, no qual o diagnóstico e os resultados são tomados como determinantes do modo de ser da criança.

\section{Referências}

Ariès, P. (1978). História social da criança e da família. Rio de Janeiro: Zahar.

Angerami, V. A. (2004). O atendimento infantil na ótica fenomenológica e existencial. São Paulo: Pioneira Thompson.

Boss, M. (1988). Angústia, culpa e libertação (4a ed.). São Paulo: Livraria Duas Cidades.

Castro, L. R. (1988). Infância e adolescência na cultura do consumo. Rio de Janeiro: NAU.

Coimbra, C. M. B. (1995). Guardiães da ordem: Uma viagem pelas práticas psi no Brasil do "milagre”. Rio Janeiro: Oficina do Autor.

Cytrynowicz, M. B. (2000). O mundo da criança. Revista da Associação Brasileira de Daseinsanalyse, 9, 74-89.

Del Priore, M. (2002). História das crianças no Brasil (3a ed.). São Paulo: Contexto.

Heidegger, M. (2005a). Ser e tempo: Parte 1 (15a ed.). Petrópolis: Vozes. (Originalmente publicado em 1927)

Heidegger, M. (2005b). A questão da técnica. In M. Heidegger, Ensaios e Conferências (pp. 11-38). Petrópolis, RJ: Vozes.

Heidegger, M. (2007). Ser e verdade. Petrópolis, RJ: Vozes.

Heidegger, M. (2008). Verdade - Ser-aí - Ser-com. In M. Heidegger, Introdução à filosofia (pp. 129-140). São Paulo: Martins Fontes.

Heywood, C. (2018). A history of childhood: Children and childhood in the West from Medieval to Modern times. Cambridge, UK: Potity press.

Mattar, C. (2015). A criança e a família: Aspectos históricos e dilemas contemporâneos. In A. M. Feijoo \& E. L. Feijoo (Orgs.), Ser criança: Uma compreensão existencial da experiência infantil. Rio de Janeiro: Edições IFEN.

Rodrigues, T. J. (2006). Terror, medo, pânico: Manifestações da angústia no contemporâneo. Rio de Janeiro: 7 Letras. 
Sá, R. N. (2017). Para além da técnica: Ensaios fenomenológicos sobre psicoterapia, atenção e cuidado. Rio de Janeiro: Via Veritá.

Veyne, P. (2009). A história da vida privada (Vol 1). São Paulo: Ed. Companhia de Bolso.

Yalom, I. D. (1980). Existential psychotherapy. New York: Basic Books.

\section{Como citar:}

Dourado, M. P. B. (2021). A Criança Contemporânea e a Noção de Cuidado: Uma Reflexão a partir da Fenomenologia Hermenêutica. Revista Subjetividades, 21(Esp 1. Psicologia \& Fenomenologia), e9492. http://doi.org/10.5020/23590777. rs.v21iEsp1.e9492

\section{Endereço para correspondência}

Maira Prieto Bento Dourado

E-mail: mairadouradopsi@gmail.com 